\title{
Factors associated with childhood ocular morbidity and blindness in three ecological regions of Nepal: Nepal pediatric ocular disease study
}

\author{
Srijana Adhikari ${ }^{1 *}$, Mohan Krishna Shrestha ${ }^{1}$, Kamala Adhikari ${ }^{2}$, Nhukesh Maharjann ${ }^{1}$ and Ujjowala Devi Shrestha ${ }^{1}$
}

\begin{abstract}
Background: Nepal Pediatric Ocular Diseases Study is a three year longitudinal population based study. Here we present the baseline survey report which aims to investigate various risk factors associated with childhood ocular morbidity and blindness in three ecological regions of Nepal.

Method: This baseline survey is a population based cross sectional study. The investigation was conducted in a district from each of the following regions: Terai, Hill and Mountain. The Village Development Committees (VDCs) from each district were selected by random sampling. Three Community health workers were given training on vision screening and identification of abnormal ocular signs in children. They conducted a house to house survey in their respected districts examining the children and gathering a standardized set of data variables. Children with abnormal vision or ocular signs were then further examined by pediatric ophthalmologists.

Results: A total of 10950 children aged 0-10 years (5403 from Terai, 3204 from the hills, 2343 from the mountains) were enrolled in the study. However $681(6.2 \%)$ were non responders. The male to female ratio was 1.03. The overall prevalence of ocular morbidity was $3.7 \%$ (95\% Cl of 3.4\%-4\%) and blindness was $0.07 \%$ (95\% Cl of 0.02\%-0.12\%). Ocular morbidity was more prevalent in the mountain region whereas blindness was more prevalent in the Terai region. Children from the Terai region were more likely to suffer from congenital ocular anomalies compared to the other regions. Children whose mother smoked, drank alcohol, or was illiterate were significantly afflicted with ocular diseases $(p<0.05)$. In addition,a higher prevalence of ocular disease was related to children with past medical history of systemic illnesses, abnormal postnatal period or missing childhood vaccinations. Blindness was more prevalent in children who suffered from a systemic illness. Females and under-nourished children were more likely to have ocular morbidity and blindness.
\end{abstract}

Conclusion: It was found that childhood blindness was more prevalent in the Terai region, the undernourished, females and in those with co-morbid systemic illnesses. This study strongly suggests that prevention of childhood blindness requires additional resources to address these disparity.

Keywords: Nepal, Blindness, Pediatric, Ocular

\section{Background}

Vision disorders are among the most common disabilities to affect children. It has been estimated that there are 1.4 million blind children worldwide, two third of whom live in the developing 6 countries like Nepal [1]. According to World Health Organization (WHO) childhood blindness is a priority, and significant component of its vision 2020

\footnotetext{
* Correspondence: srij_a@yahoo.com

${ }^{1}$ Tilganga Institute of Ophthalmology, Kathmandu, Nepal

Full list of author information is available at the end of the article
}

program [2]. Population based data on the prevalence of childhood ocular morbidity and blindness, which are needed to set priorities and to plan strategies are limited worldwide including in Nepal [3,4]. These types of studies are important in determining the magnitude of the problem and also to explore associated risk factors, which may be social, environmental and/or biological. A population based study can help establish targeted educational and screening programs in order to reduce known modifiable risk factors. Data on childhood blindness derived from the 
nationwide survey in the blind schools of Nepal has been previously reported [5]. In Nepal, it has been estimated that there are 30240 blind children and another 120000 children suffering from low vision [6]. There are also other reports addressing ocular morbidity in school children [7-9].

However, a population based survey of childhood ocular morbidity and blindness of all age groups have not yet been assessed in Nepal. Nepal Pediatric Ocular Diseases Study (NPODS) aims to fulfill this void. It is a population based three year longitudinal study which has been designed to evaluate the disease prevalence and incidence in children in a defined population from three geographically diverse districts of Nepal. The baseline survey has been completed and the goal is to report the demographic and biological risk factors associated with childhood ocular morbidity and blindness with emphasis on potentially preventable or modifiable factors.

\section{Methods}

This baseline survey is a population based cross sectional study. The study was approved by the Institutional Review Board of Tilganga Institute of Ophthalmology. It adheres to the tenets of the Declaration of Helsinki.

\section{The study area}

Nepal is divided into three geographically diverse regions: Terai in the south is a flat plane, in the central zone there are hills and in the north, the terrain is mountainous. Each region is subdivided into districts and within the districts are Village Development Committees (VDCs). One district from each region was selected: Sarlahi from the Terai region, Makawanpur from hilly region and Sindhupalchowk from the mountainous region. The number of VDCs selected for each region was in proportion to the sample size: four from the Terai, two from the hills and two from the mountainous region.

\section{The study population}

All the children from 0 to 10 years of age residing in the selected geographical areas were included in the study.

\section{Sample size and sampling method}

For sample size calculation, the formula of estimating a population proportion with specified relative precision was used in this study. Taking the ocular morbidity prevalence of $5 \%, 10 \%$ of relative precision and considering the design effect of 1.5, a total sample size of 10950 was needed for this study. The total sample size was taken from 3 selected districts proportionately according to their projected population in 2011. Based on those 2343 children from the Sindhupalchowk, 3204 from the Makawanpur and 5403 from the Sarlahi were recruited. Three districts from each ecological region were selected by the purposive sampling and the VDCs were selected by the simple random sampling method.

\section{The field examination}

One CHW was recruited from each of the three districts. They were given training on testing age specific visual acuity in children and on detecting abnormal ocular signs using a torch light. A special data collection form was designed and pretested in the similar community in the Kathmandu valley. Informed consent was taken from all the parents of children included in the study.

The CHWs conducted a house to house survey where they took a detailed history and examined each child. The history was taken from the parents and this included a maternal history (antenatal, birth and post natal, literacy, smoking and alcohol), their child's history (systemic illnesses and any previous ocular surgery or treatment) as well as known family history.

This field examination included the following:

1. Visual acuity was assessed and the method of measuring it was dependent on the age of the child. In children less than 4 years old visual acuity was measured using the fixation preference method with a torch light. Children 4-6 years of age were examined using the HOTV matching test, at three meters distance. In children aged 6 years and older, vision was assessed using the Snellen acuity chart.

2. Height and weight of the child.

3. Torch light examination to assess for five abnormal signs: red eye, head tilt, white pupillary reflex, deviation of eye and watering

4. Motility examination

5. Cover test.

\section{Examination of abnormal children}

Children were subsequently further examined by two pediatric ophthalmologists from the Tilganga Institute of Ophthalmology, if the visual acuity of the child was less than 6/9 in one or both eyes or if they presented with any abnormal ocular signs. The children were brought to an eye clinic close to their homes for this more detailed assessment.

Blindness in this study was defined as a presenting visual acuity of less than 6/60 in the better eye and visual impairment was defined as a presenting visual acuity of less than 6/18 in the better eye. Risk factors were categorized into 3 groups: demographic, maternal and the biological.

\section{Statistical analysis}

Data entry was recorded in Epi data version 3.1. Data analysis was done in the Statistical Package for Social Sciences (SPSS) 16.5 to determine if there was an association between ocular morbidity and blindness with 
Table 1 Prevalence of different ocular diseases in three ecological regions

\begin{tabular}{|c|c|c|c|c|c|c|c|c|}
\hline \multirow[t]{2}{*}{ Pattern of diseases } & \multicolumn{2}{|c|}{ Total } & \multicolumn{2}{|c|}{ Terai } & \multicolumn{2}{|c|}{ Hill } & \multicolumn{2}{|c|}{ Mountain } \\
\hline & $\mathrm{N}$ & $\%$ & $\mathrm{~N}$ & $\%$ & $\mathbf{N}$ & $\%$ & $\mathbf{N}$ & $\%$ \\
\hline Conjunctivitis (Acute and Chronic) & 162 & 43.3 & 7 & 6.0 & 18 & 23.1 & 137 & 76.1 \\
\hline Corneal opacity & 81 & 21.7 & 53 & 45.7 & 16 & 20.5 & 12 & 6.7 \\
\hline Strabismus & 50 & 13.4 & 12 & 10.3 & 16 & 16.7 & 22 & 12.2 \\
\hline Amblyopia & 35 & 9.4 & 13 & 11.2 & 13 & 16.7 & 9 & 5.0 \\
\hline Congenital ptosis & 13 & 3.5 & 9 & 7.8 & 2 & 2.6 & 2 & 1.1 \\
\hline Refractive error & 7 & 1.9 & 3 & 2.6 & 2 & 2.6 & 2 & 1.1 \\
\hline Congenital cataract/aphakia & 6 & 1.6 & 3 & 2.6 & 2 & 2.6 & 1 & 0.6 \\
\hline Choroidal coloboma & 4 & 1.1 & 4 & 3.5 & 0 & 0.0 & 0 & 0.0 \\
\hline Congenital lid and adnexal diseases & 5 & 1.3 & 0 & 0.0 & 3 & 3.9 & 2 & 1.1 \\
\hline Optic atrophy & 2 & 0.5 & 1 & 0.9 & 0 & 0.0 & 1 & 0.6 \\
\hline Retinal diseases & 3 & 0.8 & 3 & 2.6 & 0 & 0.0 & 0 & 0.0 \\
\hline Nystagmus & 4 & 1.1 & 1 & 0.9 & 1 & 1.3 & 2 & 1.1 \\
\hline Globe abnormalities & 6 & 1.6 & 4 & 3.5 & 2 & 2.6 & 0 & 0.0 \\
\hline Others & 4 & 1.1 & 1 & 0.9 & 2 & 2.6 & 1 & 0.6 \\
\hline
\end{tabular}

various suspected risk factors. A $p$ value $<0.05$ was considered significant.

\section{Results}

A total of 10,950 children were enrolled from all three districts. Out of these patients 681 (6.2\%) were non responders. Of the remaining participants $50.7 \%$ (5208) were from Sarlahi, 30.5\% (3136) were from Makawanpur and $18.8 \%$ (1926) were from Sindhupalchok. The mean age of the study population was 5.7 (SD 3.1). Thirty seven point eight percent $(37.8 \%)$ were aged between $0-5$ years old and the remainder were aged between $6-10$ years old. The male to female ratio was 1.03:1. Among the age group of $0-5$ years, $39.1 \%$ of children were in terai, $40.3 \%$ in hills and $30.4 \%$ were in mountain region. In the age group 6-10 years, there were $60.9 \%$ in terai, 59.7 in hills and $69.6 \%$ in the mountain region. The proportion of children in each group varied among the three regions.

\section{The prevalence of ocular morbidity and blindness}

Ocular morbidity was present in 374 children in total and this leads to a prevalence of $3.7 \%$ (95\% CI 3.3\%-4.0\%). Only 8 children were afflicted with more than one type of ocular morbidity. The most common ocular problem was conjunctivitis (acute or chronic) and this affected $43 \%$ of participants (Table 1).

The prevalence of blindness (defined as a presenting visual acuity (PVA) of less than 6/60) was found to be 0.07\% (95\% CI 0.02\%-0.12\%) and visual impairment (PVA less than $6 / 18$, but greater than $6 / 60$ in the better eye) was $0.1 \%$ (95\% CI of $0.04 \%-0.15 \%$ ) (Table 2).

In Table 3, it is noted that there is a significant difference ( $p$ value $<0.05$ ) in the prevalence of ocular disease between the 3 different regions. In descending order of ocular disease prevalence, the mountainous region contained the highest proportion, followed by Terai and then the hill regions.

Of interest ocular disease was significantly ( $\mathrm{p}$ value $<0.05$ ) more associated with the following variables: maternal education status, history of consanguinity, smoking and alcohol habit of the mother, children aged 6-10 years old and surprisingly with the Buddhist religion. Other variables investigated were associated with an ocular disease, but the relationship was not significant. Biological risk factors (time of birth, place of birth, type of delivery, postnatal period, immunization, previous ocular surgery, systemic illness) were also studied and many of these were found to be significantly associated with ocular diseases.

Table 2 Blindness and visual impairment in three ecological regions

\begin{tabular}{|c|c|c|c|c|}
\hline \multirow[t]{2}{*}{ Region } & \multicolumn{2}{|c|}{ Blindness } & \multicolumn{2}{|c|}{ Visual impairment } \\
\hline & Crude $(95 \% \mathrm{Cl})$ & Age adjusted $(95 \% \mathrm{Cl})$ & Crude $(95 \% \mathrm{Cl})$ & Age adjusted $(95 \% \mathrm{Cl})$ \\
\hline Terai & $0.07 \%(0.02-0.13)$ & $0.08 \%(0.02-0.13)$ & $0.09 \%(0.04-0.15)$ & $0.08 \%(0.02-0.13)$ \\
\hline Hill & $0.06 \%(0.01-0.11)$ & $0.07 \%(0.02-0.11)$ & $0.16 \%(0.06-0.24)$ & $0.17 \%(0.07-0.24)$ \\
\hline Mountain & $0.05 \%(0.02-0.11)$ & $0.06 \%(0.01-0.11)$ & 0 & 0 \\
\hline
\end{tabular}


Table 3 Factors associated with the ocular morbidity in three ecological regions

\begin{tabular}{|c|c|c|c|c|}
\hline Description & & $\begin{array}{c}\text { Ocular disease } \\
\text { present } \mathrm{N}(\%)\end{array}$ & $\begin{array}{r}\text { Ocular disease } \\
\text { absent N (\%) }\end{array}$ & $\begin{array}{r}\text { Chi-square test } \\
\text { P value }\end{array}$ \\
\hline \multicolumn{5}{|l|}{ Demographic factors } \\
\hline \multirow[t]{3}{*}{ Region } & Terai & $116(2.2 \%)$ & $5092(97.7 \%)$ & \multirow[t]{3}{*}{0.000} \\
\hline & Hill & $78(2.5 \%)$ & $3058(97.5 \%)$ & \\
\hline & Mountain & $180(9.3 \%)$ & $1746(90.7 \%)$ & \\
\hline \multirow[t]{2}{*}{ Age (years) } & $<5$ & $96(2.5 \%)$ & $3789(97.5 \%)$ & \multirow[t]{2}{*}{0.000} \\
\hline & $>=5-10$ & $278(4.4 \%)$ & $6107(95.6 \%)$ & \\
\hline \multirow[t]{2}{*}{ Sex } & Female & $172(3.4 \%)$ & $4916(96.6 \%)$ & \multirow[t]{2}{*}{0.16} \\
\hline & Male & 202(3.9\%) & 4980(96.1\%) & \\
\hline \multirow[t]{4}{*}{ Religion } & Hindu & $140(2.7 \%)$ & $5097(97.3 \%)$ & \multirow[t]{4}{*}{0.000} \\
\hline & Buddhist & $184(6.8 \%)$ & 2523(93.2\%) & \\
\hline & Christian & $15(2.5 \%)$ & $582(97.5 \%)$ & \\
\hline & Others & $35(2.0 \%)$ & 1694(98.0) & \\
\hline \multirow[t]{3}{*}{ Type of family } & Nuclear & $237(3.6 \%)$ & $6314(96.4 \%)$ & \\
\hline & Joint & $117(3.9 \%)$ & $2890(96.1 \%)$ & \multirow[t]{2}{*}{0.37} \\
\hline & Extended & $20(2.8 \%)$ & $692(97.2 \%)$ & \\
\hline \multicolumn{5}{|l|}{ Maternal factors } \\
\hline \multirow[t]{2}{*}{ History of marriage (Consanguinity) } & Yes & $175(7.0 \%)$ & 2332(93.0\%) & \multirow{2}{*}{0.000} \\
\hline & No & $199(2.6 \%)$ & $7555(97.4 \%)$ & \\
\hline \multirow[t]{2}{*}{ Mothers education } & Literate & $117(3.0 \%)$ & 3733(97.0) & \multirow{2}{*}{0.006} \\
\hline & Illiterate & $257(4.0 \%)$ & 6163(96\%) & \\
\hline \multirow[t]{2}{*}{ Mother's smoking habit } & Yes & $117(3.0 \%)$ & $3742(97.0 \%)$ & \multirow{2}{*}{0.01} \\
\hline & No & $257(4.0 \%)$ & 6154(96.0\%) & \\
\hline \multirow[t]{2}{*}{ Mother's alcohol habit } & Yes & $142(7.1 \%)$ & 1883(92.9\%) & \multirow[t]{2}{*}{0} \\
\hline & No & $2326(2.8 \%)$ & $8013(97.2 \%)$ & \\
\hline \multirow[t]{2}{*}{ ANC period } & Uneventful & $339(3.7 \%)$ & 8774(96.3\%) & \multirow{2}{*}{0.23} \\
\hline & Eventful & $35(3.0 \%)$ & $1122(97.0 \%)$ & \\
\hline \multicolumn{5}{|l|}{ Biological factors } \\
\hline \multirow[t]{2}{*}{ Birth history } & Full term & $373(3.6 \%)$ & $9885(96.4 \%)$ & \multirow{2}{*}{0.48} \\
\hline & Preterm & $1(14.3 \%)$ & $10(85.7 \%)$ & \\
\hline Place of birth & Home & $348(3.7 \%)$ & 8949(96.3\%) & م م \\
\hline & $\mathrm{HF}$ & $26(2.7 \%)$ & $947(97.3 \%)$ & 0.9 \\
\hline Type of delivery & Normal & $372(3.6 \%)$ & $9825(96.4 \%)$ & \\
\hline & Forceps & $1(4.3 \%)$ & $22(95.7 \%)$ & 093 \\
\hline & Vacuum & $0(0)$ & $3(100 \%)$ & 0.93 \\
\hline & $\mathrm{C} / \mathrm{S}$ & $1(2.1 \%)$ & $46(97.9 \%)$ & \\
\hline Postnatal period & Uneventful & $370(3.6 \%)$ & $9881(96.4 \%)$ & م \\
\hline & Eventful & $4(21.1 \%)$ & $15(78.9 \%)$ & 0.000 \\
\hline Immunization & Yes & $360(3.5 \%)$ & $9797(96.5 \%)$ & م000 \\
\hline & No & $14(12.4 \%)$ & $99(87.6 \%)$ & \\
\hline Previous ocular surgery/treatment & Yes & $10(21.7 \%)$ & $36(78.3 \%)$ & م م000 \\
\hline & No & $364(3.6 \%)$ & $9860(96.4 \%)$ & \\
\hline Systemic illness & Yes & $5(23.8 \%)$ & $16(76.2 \%)$ & 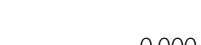 \\
\hline & No & $369(3.6 \%)$ & 9879(96.4\%) & .000 \\
\hline
\end{tabular}


The multiple logistic regression analysis was done to determine the association of ocular morbidity with various risk factors. Compared to the Terai region, the likelihood of having an ocular disease in the mountainous region was significantly more than 2 times higher (OR: 2.19, 95\% CI: 1.48-3.26), whereas it was non-significantly less likely (OR: $0.79,95 \% \mathrm{CI}: 0.51-1.22)$ in the hilly region (Table 4).

Table 5 shows the association of visual impairment and blindness with measured risk factors. Both visual

Table 4 Association of ocular disease and risk factors (Multiple Logistic regressions for risk factors)

\begin{tabular}{|c|c|c|}
\hline Risk factors & OR $(95 \% \mathrm{CI})$ & $P$ value \\
\hline \multicolumn{3}{|l|}{ Region } \\
\hline Terai & 1 & - \\
\hline Hill & $0.79(0.51-1.22)$ & 0.295 \\
\hline Mountain & $2.19(1.48-3.26)$ & 0.001 \\
\hline \multicolumn{3}{|l|}{ Age group (years) } \\
\hline $0-5$ years & 1 & - \\
\hline$>5-10$ & $1.52(1.2-1.92)$ & 0.001 \\
\hline \multicolumn{3}{|l|}{ Religion } \\
\hline Hindu & 1 & - \\
\hline Buddhist & $1.81(1.32-2.49)$ & 0.001 \\
\hline Christian & 1.3(0.71-2.37) & 0.4 \\
\hline others & $0.88(0.59-1.32)$ & 0.544 \\
\hline \multicolumn{3}{|l|}{ Mother's habit of alcohol intake } \\
\hline No & 1 & \\
\hline Yes & $1.22(0.94-1.57)$ & 0.13 \\
\hline Mother's education status & 1 & \\
\hline \multicolumn{3}{|l|}{ Literate } \\
\hline Illiterate & $1.37(1.09-1.71)$ & 0.97 \\
\hline Mothers history of marriage & & 0.04 \\
\hline Consanguinity & 1 & \\
\hline Non consanguinity & $0.26(0 . .21-0.33)$ & \\
\hline Immunization status & & 0.001 \\
\hline Immunized & 1 & \\
\hline Non-immunized & $2.95(1.63-5.36)$ & \\
\hline Systemic illness & & 0.001 \\
\hline Present & 1 & \\
\hline Absent & $0.1(0.04-0.23)$ & \\
\hline Previous ocular surgery/treatment & & 0.001 \\
\hline Yes & 1 & \\
\hline No & $0.11(0.06-0.22)$ & \\
\hline Postnatal period & & 0.01 \\
\hline Non eventful & 1 & \\
\hline Eventful & $5.33(1.45-17.02)$ & \\
\hline
\end{tabular}

OR: Odds Ratio, Cl confidence interval. impairment and blindness were common in patients aged between $6-10$ years old. More than two thirds of visual impairment cases were seen in male patients whereas blindness was more common in female children. Sixty percent of visual impairment cases were seen in children who practiced Hinduism and $42.9 \%$ of blind cases were prevalent in the other religions.

Both visual impairment and blindness were more prevalent in the children whose mother was illiterate and whose mother smoked and drank alcohol. All children with visual impairment and blindness were delivered at full term and had no history of pregnancy and postnatal complications. However, some cases of visual impairment were found in the children with systemic illness (4.8\%) and with a previous history of ocular treatment (2.2\%). Similarly, blindness was found in $8.7 \%$ of children with a previous history of treatment for any eye diseases. There was a significant relationship $(\mathrm{p}<0.05)$ between blind children who had a history of ocular disease. In addition, visually impaired children were significantly associated with a previous history of ocular surgery or treatment, systemic illness or complicated antenatal period.

The association between nutritional status and ocular morbidity was measured. The mean BMI of all the children was 16.3 (SD 5.7). In Terai, 15.21 (SD 5.6), 16.7 (SD 3.7) in hills and 15.7 (SD 8.0) in the mountains. Overall the majority of children (85.8\%) were underweight whereas only $2.2 \%$ were obese. Among the total children with ocular morbidity, the majority 317 (90.1\%) were underweight. Not surprisingly, more than $90 \%$ (73 of the 81 cases) of children with the corneal opacities were under nourished (Table 6).

\section{Discussion}

The causes of ocular morbidity and blindness vary across countries as they have different environmental variables, socioeconomic, geographic and ethnic backgrounds. It may also be affected by the child's own biological factors and their total wellbeing. Nepal et al. has shown that refractive error is the most common ocular morbidity in children [7]. However there is a regional disparity; Pokhrel et al. and Shrestha et al. showed that children from rural areas are less likely to have refractive error than children from urban areas $[8,10]$. These studies however are mainly focused on the prevalence and causes of ocular diseases but not the risk factors associated with them. Jyoti et al. did a nationwide survey in blind schools, showing that corneal blindness due to Vitamin A deficiency is a major cause of childhood blindness [5]. However, unlike our study it was not population based and they mainly highlighted the etiology and did not focus on elucidating the risk factors.

Our study has found that ocular morbidity was more prevalent in the mountainous region. Conjunctivitis was 
Table 5 Factors associated with visual impairment and blindness

\begin{tabular}{|c|c|c|c|c|}
\hline \multirow[t]{2}{*}{ Characteristics } & \multicolumn{2}{|c|}{ Visual impairment } & \multicolumn{2}{|c|}{ Blindness } \\
\hline & Yes & No & Yes & No \\
\hline \multicolumn{5}{|c|}{ Demographic factors } \\
\hline \multicolumn{5}{|l|}{ Region } \\
\hline Terai & $5(50.0 \%)$ & $5203(50.7 \%)$ & $4(57.1 \%)$ & $5204(50.7 \%)$ \\
\hline Hill & $5(50.0 \%)$ & $3131(30.5 \%)$ & $2(28.6 \%)$ & $3134(30.5 \%)$ \\
\hline Mountain & $0(0 \%)$ & 1926(18.8\%) & $1(14.3 \%)$ & 1925(18.8\%) \\
\hline \multicolumn{5}{|l|}{ Age group } \\
\hline$<5$ years & $1(10 \%)$ & $3884(37.9 \%)$ & $1(14.3 \%)$ & $3884(37.8 \%)$ \\
\hline$>=5-10$ years & $9(90.0 \%)$ & $6376(62.1)$ & $6(85.7 \%)$ & $6379(62.2 \%)$ \\
\hline \multicolumn{5}{|l|}{ Sex } \\
\hline Female & $2(20.0 \%)$ & $5086(49.6 \%)$ & $4(57.1 \%)$ & $5084(49.5 \%)$ \\
\hline Male & $8(80.0 \%)$ & $5174(50.4 \%)$ & $3(42.9 \%)$ & $5179(50.5 \%)$ \\
\hline \multicolumn{5}{|l|}{ Religion } \\
\hline Hindu & $6(60.0 \%)$ & $5231(51.0 \%)$ & $2(28.6 \%)$ & $5235(51.0 \%)$ \\
\hline Buddhist & $1(10 \%)$ & $2706(26.4 \%)$ & $1(14.3 \%)$ & $2706(26.4 \%)$ \\
\hline Christian & $1(10.0 \%)$ & $596(5.8 \%)$ & $1(14.3 \%)$ & $596(5.8 \%)$ \\
\hline Others & $2(20.0 \%)$ & $1727(16.8 \%)$ & $3(42.9 \%)$ & $1726(16.8 \%)$ \\
\hline \multicolumn{5}{|c|}{ History of marriage (Consanguinity) } \\
\hline Yes & 0 & $1766(17.2 \%)$ & $2(28.6 \%)$ & $1764(17.2 \%)$ \\
\hline No & $10(100 \%)$ & $8494(82.8 \%)$ & $5(71.4 \%)$ & 8499(99.9\%) \\
\hline \multicolumn{5}{|l|}{ Maternal factors } \\
\hline \multicolumn{5}{|l|}{ Mothers education } \\
\hline Literate & $4(40 \%)$ & $3846(37.5 \%)$ & $2(28.6 \%)$ & $3848(37.5 \%)$ \\
\hline Illiterate & $6(60 \%)$ & $6414(62.5 \%)$ & $5(71.4 \%)$ & $6415(62.5 \%)$ \\
\hline \multicolumn{5}{|c|}{ Mother's smoking habit } \\
\hline Yes & $6(60.0 \%)$ & $6405(62.4 \%)$ & $5(71.4 \%)$ & $6406(62.4 \%)$ \\
\hline No & $4(40.0 \%)$ & $3855(37.6 \%)$ & $2(28.6 \%)$ & $3857(37.6 \%)$ \\
\hline \multicolumn{5}{|c|}{ Mother's alcohol habit } \\
\hline Yes & $8(80 \%)$ & $8237(80.3 \%)$ & $5(71.4 \%)$ & $8240(80.3 \%)$ \\
\hline No & $2(20 \%)$ & 2023(19.7\%) & $2(28.6 \%)$ & 2023(19.7\%) \\
\hline ANC period & * & & & \\
\hline Uneventful & $6(60.0 \%)$ & $9107(88.8 \%)$ & $7(100 \%)$ & $9106(88.7 \%)$ \\
\hline Eventful & $4(40.0 \%)$ & $1153(11.2 \%)$ & $0(0)$ & $1157(11.3 \%)$ \\
\hline \multicolumn{5}{|l|}{ Biological factors } \\
\hline \multicolumn{5}{|l|}{ Birth history } \\
\hline Full term & $10(100 \%)$ & 10248(99.9\%) & 7(100\%) & $10251(99.9 \%)$ \\
\hline Preterm & $0(0)$ & $12(.1 \%)$ & $0(0 \%)$ & $12(.1 \%)$ \\
\hline \multicolumn{5}{|l|}{ Place of birth } \\
\hline Home & $9(90 \%)$ & 9288(90.5\%) & 7(100\%) & $9290(90.5 \%)$ \\
\hline $\mathrm{HF}$ & $1(10 \%)$ & $972(9.5 \%)$ & $0(0 \%)$ & $973(9.5)$ \\
\hline \multicolumn{5}{|l|}{ Postnatal period } \\
\hline Uneventful & $10(100 \%)$ & $10241(99.8 \%)$ & $7(100 \%)$ & 10244(99.8\%) \\
\hline Eventful & O(0\%) & $19(0.2 \%)$ & $0(0 \%)$ & $19(0.2 \%)$ \\
\hline
\end{tabular}


Table 5 Factors associated with visual impairment and blindness (Continued)

\begin{tabular}{|c|c|c|c|c|}
\hline \multicolumn{5}{|l|}{ Immunization } \\
\hline Yes & $10(100 \%)$ & 10147(98.9\%) & $7(0.1 \%)$ & 10150(98.9\%) \\
\hline No & $0(0 \%)$ & 113(1.1\%) & $0(0 \%)$ & 113(1.1\%) \\
\hline Systemic illness & $* * *$ & & & \\
\hline Yes & $1(4.8 \%)$ & $20(95.2 \%)$ & $0(0 \%)$ & $21(100 \%)$ \\
\hline No & $9(0.1 \%)$ & 10240(99.9\%) & $7(0.1 \%)$ & 10242(99.9\%) \\
\hline Previous ocular surgery/treatment & $* * *$ & & $* * *$ & \\
\hline Yes & $1(2.2 \%)$ & $45(97.8 \%)$ & $4(8.7 \%)$ & $42(91.3 \%)$ \\
\hline No & $9(0.1 \%)$ & 10215(99.9\%) & $3(0.1 \%)$ & $10221(99.9 \%)$ \\
\hline
\end{tabular}

Note: ${ }^{* *} p<0.001,{ }^{*} p<0.05$.

the most common disease in this region. This is similar to other studies conducted in the high mountains of Tibet and India [11,12]. On the other hand, congenital abnormalities were more common in the flat terrain of the Terai region. Most congenital diseases have a genetic etiology and it is known that there are many families in this region who practice consanguineous marriage suggesting a possible reason for this higher regional prevalence. Further genetic studies are needed to support this statement.

Children aged 6-10 years old had a higher prevalence of ocular morbidity compared to the younger age group, suggesting that an older age is a risk factor. Conjunctivitis is the most common ocular morbidity in our study and is commonly present in children of this age group. It was also found that there was a strong correlation between ocular diseases and the Buddhist community. Given that most Buddhists in Nepal are originally from the mountains and this study highlights that ocular morbidity was higher from the mountainous region, this may explain why 2 ocular morbidity was more prevalent in the Buddhist community compared to others. Further large scale study will be needed to prove causalty.

Among the maternal factors we found that maternal education, history of consanguinity and maternal history of alcohol consumption were strongly associated with ocular morbidity. However there was an inverse relationship with the maternal history of smoking. There are few studies which show a strong correlation between childhood ocular morbidity and the maternal history of smoking which contradict the findings in this study [13-15]. Also, the millennium cohort study [15] found that the mother's education has an inverse relationship with ocular diseases, again contrary to the results of this study. The history of smoking and alcohol during the antenatal was taken by the field workers (CHW). They had to rely on the information shared by the mother. This recall bias therefore is a limitation of our study.

We found a significant relationship between ocular diseases and the post natal complications such as birth asphyxia, delayed milestones and prematurity. Also there was a relationship between ocular morbidity and systemic illness such as seizure disorder. These findings are similar to Millennium Cohort and Alspac Study [14.15].

While analyzing the risk factors associated with blindness in these children, we found that blindness was more prevalent in the Terai region, in the female population in children of older age group, with a history of consanguinity and with an illiterate mother. However these factors were not statistically significant. There was a strong association between blindness and a previous history of ocular diseases or treatment. Rahi et al. stated that prenatal factors were found in about $60 \%$ of blind children, in the blind school of India [16].

In this study, the factors which are not significantly associated may be better evaluated by increasing the sample size. One important finding in our study was the association between nutritional status and ocular 22 diseases. Approximately 75\% of children were undernourished and within this group $81 \%$ children had ocular diseases. Also a significant association was found between corneal opacity with a poor nutritional status of the child. Corneal opacities were present in $22 \%$ of children who had ocular disorders and $85 \%$ of children with corneal

Table 6 Nutritional status and ocular morbidity

\begin{tabular}{lllll}
\hline BMI & Frequency & Percent & Presence of ocular disease & Corneal opacity \\
\hline Under weight $(<=17.50 \mathrm{~kg} / \mathrm{m} 2)$ & 7741 & 75.4 & $296(81.3 \%)$ & $68(85.0 \%)$ \\
Normal weight $(>17.50-22.99 \mathrm{~kg} / \mathrm{m} 2)$ & 2023 & 19.7 & $56(15.5 \%)$ & $11(13.5 \%)$ \\
Over weight $(23.00-27.99 \mathrm{~kg} / \mathrm{m} 2)$ & 310 & 3.0 & $10(2.7 \%)$ & $1(1.2 \%)$ \\
Obesity $(>28 \mathrm{~kg} / \mathrm{m} 2)$ & 141 & 1.4 & $2(0.5 \%)$ & 0 \\
\hline
\end{tabular}


opacities were undernourished. The association between the corneal opacities and malnutrition has been well reported in the literature $[17,18]$. In Nepal the national Xerophthalmia survey was done in 1985 which showed that the prevalence of corneal opacities was 0.03\% [19]. Another study, done by Shakya SR et al. in Eastern Nepal showed that corneal opacities were found in $0.2 \%$ of children with nutritional deficiencies [20]. It is known that under-nutrition and its aftermath are still a public health problem in Nepal despite interventional programs.

\section{Conclusion}

Regional disparity is evident in Nepal; ocular morbidity is more common in the mountainous regions, whereas blindness is more prevalent in the Terai region. Many children from the Terai region suffer from congenital abnormalities and this may be related to consanguinity. This needs further genetic analysis. To prevent unnecessary blindness in children, policy makers should prioritize their resources to improve perinatal care and to support nutritional interventions.

\section{Competing interests}

All authors declare that they have no competing interests.

\section{Authors' contributions}

SA carried out the research as principle investigator, and drafted the manuscript. MKS contributed in study concept, research design, and manuscript writing KA Contributed in study design and statistical analysis. NM Contributed in data collection, cleaning and statistical analysis. US contributed in manuscript writing. All authors read and approved the final manuscript.

\section{Acknowledgment}

We acknowledge The Fred Hollows Foundation for providing research grant to carry out this study. We would like to acknowledge Ms Kate Starr, a Medical Graduate from United Kingdom and Dr Anya Gushchin from University of Utah, USA who helped us in language editing services.

\section{Author details}

${ }^{1}$ Tilganga Institute of Ophthalmology, Kathmandu, Nepal. ${ }^{2}$ Freelance, Epidemiologist, Kathmandu, Nepal.

Received: 12 May 2014 Accepted: 14 October 2014

Published: 23 October 2014

\section{References}

1. World Health Organization: Programme for the Prevention of Blindness and Deafness, and International Agency for Prevention of Blindness. Geneva: WHO; 2000. Contract No.: (WHO/PBL/00.77).

2. World Health Organization: Global initiative for the elimination of avoidable blindness. In Programme for the Prevention of Blindness and Deafness. Geneva: WHO; 1997. Contract No.: (WHO/PBL/97.61).

3. Steinkuller PG, Du L, Gilbert C, Foster A, Collins ML, Coats DK: Childhood blindness. J AAPOS 1999, 3:26-32.

4. Dandona L, Gilbert CE, Rahi JS, Rao GN: Planning to reduce childhood blindness in India. Indian J Ophthalmol 1998, 46:117-122.

5. Shrestha JB, Gnyawali S, Upadhyay MP: Causes of blindness and visual impairment among students in integrated schools for the blind in Nepal. Ophthalmic Epidemiol 2012, 19:401-406.

6. $邓$ : Apex Body for Eye Health Ministry of Health and Population Nepal. Mid term review of vision 2020 2011, the right to sight, Kathmandu, Nepal.

7. Nepal BP, Koirala S, Adhikary S, Sharma AK: Ocular morbidity in schoolchildren in Kathmandu. Br J Ophthalmol 2003, 87:531-534.
8. Pokharel GP, Negrel AD, Munoz SR, Ellwein LB: Refractive Error Study in Children: results from Mechi Zone, Nepal. Am J Ophthalmol 2000, 129:436-444.

9. Pokharel A, Pokharel PK, Das H, Adhikari S: The patterns of refractive errors among the school children of rural and urban settings in Nepal. Nepal J Ophthalmol 2010, 2:114-120.

10. Shrestha RK, Joshi MR, Ghising R, Rizyal A: Ocular morbidity among children attending government and private schools of Kathmandu valley. JNMA J Nepal Med Assoc 2011, 51:182-188.

11. Lu P, Chen X, Zhang W, Chen S, Shu L: Prevalence of ocular disease in Tibetan primary school children. Can J Ophthalmol 2008, 43:95-99.

12. Jha KN: Spectrum of ocular diseases at a Military Hospital in Ladak North India. J Clin Diagn Res 2008, 3:843-846.

13. Ganz ML, Xuan Z, Hunter DG: Prevalence and correlates of children's diagnosed eye and vision conditions. Ophthalmology 2006, 113:2298-2306.

14. Williams C, Northstone K, Howard M: Prevalence and risk factors for common vision problems in children: data from the ALSPAC study. $\mathrm{Br} J$ Ophthalmol 2008, 92:959-964.

15. Cumberland PM, Pathai S, Rahi JS: Millennium Cohort Study Child Health Group. Prevalence of eye disease in early childhood and associated factors: findings from the millennium cohort study. Ophthalmology 2010, 117:2184-2190. e1-3.

16. Rahi JS, Sripathi S, Gilbert CE, Foster A: The importance of prenatal factors in childhood blindness in India. Dev Med Child Neurol 1997, 39:449-455.

17. Gilbert CE, Shah SP, Jadoon MZ, Bourne R, Dineen B, Khan MA: Poverty and blindness in Pakistan: results from the Pakistan national blindness and visual impairment survey. BMJ 2008, 336:29-32.

18. Reddy V, Rao V, Arunjyothi, Reddy M: Conjunctival impression cytology for assessment of vitamin A status. Am J Clin Nutr 1989, 50:814-817.

19. Upadhyay MP, Gurung BJ, Pillai KK, Nepal BP: Xerophthalmia among Nepalese children. Am J Epidemiol 1985, 121:71-77.

20. Shakya SR, Bhandary S, Pokharel PK: Nutritional status and morbidity pattern among governmental primary school children in the Eastern Nepal. Kathmandu Univ Med J (KUMJ) 2004, 2:307-314.

doi:10.1186/1471-2415-14-125

Cite this article as: Adhikari et al:: Factors associated with childhood ocular morbidity and blindness in three ecological regions of Nepal: Nepal pediatric ocular disease study. BMC Ophthalmology 2014 14:125.

\section{Submit your next manuscript to BioMed Central and take full advantage of:}

- Convenient online submission

- Thorough peer review

- No space constraints or color figure charges

- Immediate publication on acceptance

- Inclusion in PubMed, CAS, Scopus and Google Scholar

- Research which is freely available for redistribution 